\title{
Digital transformation of energy management systems on railway transport.
}

\author{
Serk Mukhambetov \\ Engineering, humanities, natural- \\ sciences and general professional \\ disciplines \\ Branch of Federal State Budget \\ Educational Institution of Higher \\ Education «Samara State University of \\ Railway Transport» in Saratov \\ Saratov, Russia \\ mslava5@mail.ru \\ Vadim Koscheyev \\ Department of Construction Economics \\ and Housing and Utility Infrastructure \\ Saint Petersburg State University of \\ Architecture \\ and Civil Engineering \\ Saint Petersburg, Russia \\ npmos@bk.ru
}

\author{
Irina Popova \\ Engineering, humanities, natural- \\ sciences and general professional \\ disciplines \\ Branch of Federal State Budget \\ Educational Institution of Higher \\ Education \\ Samara State University of Railway \\ Transport \\ Saratov, Russia \\ impopova@mail.ru
}

\author{
Igor Danilov \\ Department of Mechanical and \\ Instrumental Engineering \\ Peoples' Friendship University of \\ Russia \\ Moscow, Russia \\ danilov-ik@rudn.ru
}

\begin{abstract}
Digital transformation of railway transport management systems opens new opportunities allowing to improve efficiency of rail shipments being one of the main modes of transportation for various industries and for passenger transportation as well. Practical implementation of dynamic energy management principles is one of the most important directions of transport sphere digital transformation. This article is addressing the procedure of railway transport energy management within targeted time frame on the basis of developed algorithms and models which may be used as a keystone for implementation of digital tools for power supply systems management. The paper is proposing to evaluate efficiency of controlling actions from the viewpoint of (i) aggregate damage minimization by means of mathematical modeling of forecasting processes and (ii) damage assessment in the entire time interval. As a result, criteria of prediction accuracy and basic parameters influence thereon have been defined. The paper describes methods to select facilities for energy management and derives mathematical models enabling the researcher to fairly disclose specific features of electrical power consumption on railway transport on the basis of implementation of energy management digital algorithms.
\end{abstract}

Keywords - railway transport, energy consumption, digital transformation, digital technologies, digital model.

\section{INTRODUCTION.}

Digital transformation of economy, different branches of industry and techno sphere as a whole is a crucial task requiring breakthrough technical and technological solutions of the $21_{\text {st }}$ century becoming accessible in view of the sixth wave of innovation. Currently, improvement of power consumption efficiency is one of targets enabling formation of modern and innovative industrial environment. According to case studies presented at World Economic Forum the scope of investments in various digital platforms, "smart" devices, and innovative technologies of data analysis in the sphere of energy consumption is reaching 1.3 billion US dollars worldwide [1].

In the forthcoming decade, main trends in the transport sphere will be represented by autonomous transport vehicles, development of innovative technologies in the sphere of energy consumption and formation of sharing economy associated with multiple-access to goods and services [2]. While projects associated with railway transport digitization fulfilled abroad are given important role digitization of railway sphere is in the early stage of development in Russia, despite the fact that digital transformation is already a leading trend in industry and economy on the whole [3].

Reduction of specific costs relating to the process of railway transportation and to the transport industry on the whole is a crucial task. At that, standardizing of fuel and energy resources (FER) consumption with a purpose to improve efficiency of usage thereof with minimum costs requires a science-based approach. One of the ways enabling resolution of the aforesaid problem consists in digital technologies promotion with a purpose to enable large-scale transformation of transport sphere which demands development of improved mathematical models in the sphere of energy management systems on railway transport.

\section{TARGET SETTING.}

According to experts, energy demand during 2016-2025 will annually increase by $2.4 \%$ and will reach the level of 26500 terawatt-hours by the end of that period; compound growth will reach about $24 \%$, therefore, it will be essential to solve global energy saving issues as soon as possible [4]. Where it is impossible to drive down the demand for energy resources best way to solve this problem will consist in developing the methods of energy efficiency processes 
improvement, inter alia, through development of industrial and transport facilities management systems.

According to experts, advancement of modern energy management technologies in the sphere of industry will make it possible to reduce consumption of power resources by $12 \%$ and thus considerably lower carbon dioxide emissions to the atmosphere (to 2 billion tons) by 2030 which is currently one of the crucial environmental protection tasks worldwide [5]. Monetary effect of industrial development through energy consumption processes optimization may reach about 2 trillion US dollars [1] and this will make it possible to reduce greenhouse gases emissions, create new working places and facilitate establishing of digital economy on the basis of modern technological solutions. Moreover, it was discovered within the framework of the Global e Sustainability Initiative (GESI) that advancement of information-communication technologies in transport sphere including railways will reduce energy consumption by 4.9 trillion US dollars by 2030 [6].

However, the problem of technological support for digital transformation of energy consumption processes in the sphere of transport has not been yet solved due to its complicacy and multiformity. Insufficiently profound analysis of the process of electric energy consumption by railway facilities, limited employment of efficient mathematical models, algorithms and modern technical devices in management are stipulating importance of the research in this direction.

Significant factor of improving economic efficiency of railway transportation is development of methods, models, algorithms and technical devices enabling efficient energy consumption management [7].

While developing the energy management principles this system of control is often represented as a combination of the following subsystems: decision making, functional and information. That is why, synthesis of energy management system (as a kind of FER) consists in [8]:

- $\quad$ synthesis of prompter-system structure, i.e. decision making;

- establishment of system possessing the required quantity of functions capable to manage energy consumption and to link these functions;

- formation of technical-organizational and information systems for railways sphere.

Total energy comparison (TEC), classical energy intensity (CEI) and liner regression models (LRM) are three most frequently used approaches used to track energy characteristics of industrial facilities [9].

Problem of optimized power distribution (OPD) is considered in order to minimize instantaneous operational costs, additional costs and transmission line losses with account to various grid limitations [10].

Therefore, implementation of system-based approach to energy management efficiency improvement on railway transport and to intellectualization of this process management is a crucial issue for digitization of processes employed on railway transport. Purpose of this article is to solve the problem of intensification of transport sphere digital transformation on the basis of improvement of energy management model on the railway transport.

\section{INVESTIGATION METHODOLOGY.}

Within the framework of the research presented herein we are solving the problem of optimization of railway transport energy consumption aiming to intensify digital transformation of the transport sphere and, therefore, we are considering various mathematical models intended for this sphere.

Where there are considerable departures of actual energy consumption from target values it is essential to foresee (on the road level) the functions of active interference in the process of energy management, i.e. to implement the function of operative energy management at any specific moment.

Energy management system on railway transport includes two levels: first level - the point of connection (traction substation, transformer substation), second level - the level of regulation (traction and non-traction consumers).

Equipment of the first level performs (in specified intervals) $\Delta t$ data collection from the metering devices of automated power consumption measurement system. Simultaneously with that, evaluation and calculation of actual electrical energy consumption for each consumer is performed (lower circuit).

Discrete dynamic models of managed systems are representing important (from theoretical and practical viewpoint) class of mathematical models enabling the researcher to cover a wide range of actual objects and management tasks compatible therewith [11].

Power consumption prediction affects $W_{p r} \in W$ controlling actions preparation decisions. At that, the $\mathrm{W}$ set (scope of consumption) of probable values is divided into the following subsets:

$$
\begin{aligned}
& \mathrm{M}_{1}=\left\{W_{p r} \geq W_{L}^{B}\right\} ; \\
& \mathrm{M}_{2}=\left\{W_{L}^{H}<W_{p r}<W_{L}^{B}\right\} ; \\
& \mathrm{M}_{3}=\left\{W_{L}^{H} \geq W_{p r}\right\},
\end{aligned}
$$

where $W_{L}^{H}$ e $W_{L}^{B}$ - lower and upper limitations of specified resource consumption.

For each of the aforementioned subsets it is possible to identify measures representing actions exerted on management objects. Upper limitation value (of energy consumed) is set up by maximum energy consumption $W_{\max }^{k}$.

Belonging of forecasted value $\mathrm{W}_{\mathrm{pr}}$ to one of subsets $\mathrm{M}_{1}$, $\mathrm{M}_{2}, \mathrm{M}_{3}$ must lead to elaboration of the most efficient measure or respective action.

Improvement of economic efficiency of transportation process represented by implementation of measures on the second level may be reduced to solving of the below problems:

- forecasting of consumed resource value (in our case electrical energy); 
- identification (selection) of consumers-regulators to enable management of total energy consumption;

- maintaining of specified energy consumption values (with set up timing and volume characteristics) by consumers-regulators.

In view of the fact that the formation of energy consumption on railway transport, in industry and other sectors of economy $[12,13,14]$ is taking place under the impact of numerous time-irregular factors it becomes expedient to determine the trends of this formation process variation [15]. For this purpose we can use polynomial models:

$$
W(t)=\sum_{i=0}^{q} \alpha_{i} t^{i},
$$

where $\alpha_{i}$ - unknown parameters of the model defined; $\mathrm{q}$ - polynomial degree.

Here, any random fluctuation is taken into account as prediction ambiguity zone and set up by means of properly established confidential interval.

In the simplest case, for prediction $\mathrm{W}(\mathrm{t})$ we will accept a quadratic model [8]:

$$
W_{T}(t)=a_{0}+a_{1} t+a_{2} t^{2},
$$

where $a_{0}, a_{1}, a_{2}-$ model parametric coefficients, $t-$ current time.

Values $\mathrm{a}_{0}, \mathrm{a}_{1}, \mathrm{a}_{2}$ of model parameters ( 3 ) may be defined with the use of least square method (LSM). This method has been best of all developed in terms of the theory and allows to obtain unbiased, consistent and (in case of independent residual) effective evaluations. However, this method is not the only one.

The moving average method is used where total energy consumption is controlled by non-traction consumersregulators. Weak point of this method is impossibility to account for cyclic changes of the range of analyzed values of total electrical energy consumption (for instance, variation of energy consumption during work and night time). As an alternative, we can use modification of this method i.e. moving average method with correction:

$$
W_{\mathrm{pr}}^{t, T}=W^{t}+(\overline{\Delta W})_{\mathrm{p}}^{t}(\varphi(T)-\varphi(t))+(\overline{\Delta W})_{\mathrm{nr}}^{t}(\psi(T)-\psi(t)),
$$

where $W_{\mathrm{pr}}^{t, T}$ - predicted energy consumption as of the end of time interval $\mathrm{T}$, at specified moment $\mathrm{t}$;

$W^{t}$ - current energy consumption at specified moment $\mathrm{t}$;

$$
(\overline{\Delta W})_{\mathrm{p}}^{t}=\frac{1}{l} \sum_{s: \varphi(t)-\varphi(s-1) \leq l} \Delta W^{s}(\varphi(s)-\varphi(s-1)) \text { - average value of }
$$
energy consumption increment $\Delta W^{s}$ exactly for 1 working day which were preceding the moment $\mathrm{t}$ of the working days;

$$
(\overline{\Delta W})_{\mathrm{nr}}^{t}=\frac{1}{l} \sum_{s: \psi(t)-\psi(s-1) \leq l} \Delta W^{s}(\psi(s)-\psi(s-1)) \text { - average value of }
$$

energy consumption increment $\Delta W^{s}$ exactly for 1 working day which were preceding the moment $t$ of the days off; $\varphi(t)=m_{\mathrm{p}}$ - working days from the beginning of interval till moment $\mathrm{t}$;

$\psi(t)=m_{\mathrm{pr}}$ - days off from the beginning of interval till moment $\mathrm{t}$;

$\varphi(T)=n_{\mathrm{p}}$ - working days from the moment $\mathrm{t}$ till moment $\mathrm{T}$;

$\psi(T)=n_{\mathrm{nr}}$ - days off from moment t till the moment $\mathrm{T} ;$

Presented forecasting method is calculating variation of particular constituents of total energy consumption with consideration of specific load schedules of particular groups of consumers (for instance, variation of consumption by nontraction enterprise or particular facility).

Where input data are insufficient it is possible to use Brown's method (Brown's filters). According to the aforesaid method, anticipated value of function $\mathrm{W}(\mathrm{t})$ may be expressed by Taylor series:

$$
W_{t+\Delta t}=W_{t}+\frac{d W}{d t} \Delta t+\frac{1}{2 !} \frac{d^{2} W}{d t^{2}} \Delta t^{2}+\ldots+\frac{1}{n !} \frac{d^{n} W}{d t^{n}} \Delta t^{n},
$$

whose members are connected by recurrence formula

$$
S_{t}^{n}(W)=\alpha S_{t}^{n-1}(\mathrm{~W})+(1-\alpha) S_{t-1}^{n}(W),
$$

which defines the average of $\mathrm{n}$-order for range $\mathrm{W}(\mathrm{t})$. Smoothing parameter $\alpha \in[0,1]$ takes into account the impact exerted by initial series of observations on the results of forecasting.

For Brown's second-order filter the following relations take place [8]:

$$
\begin{aligned}
& \mathrm{W}_{\mathrm{t}}=\mathrm{a}_{0}=3 \mathrm{~S}_{\mathrm{t}}(\mathrm{W})-3 \mathrm{~S}_{\mathrm{t}}^{2}(\mathrm{~W})+\mathrm{S}_{\mathrm{t}}^{3}(\mathrm{~W}) ; \\
& \frac{\mathrm{dW}}{\mathrm{dt}}=\mathrm{a}_{1}=\frac{\alpha^{2}}{2(1-\alpha)^{2}}\left((6-5 \alpha) \mathrm{S}_{\mathrm{t}}(\mathrm{W})-2(5-4 \alpha) \mathrm{S}_{\mathrm{t}}^{2}+(4-3 \alpha) \mathrm{S}_{\mathrm{t}}^{3}(\mathrm{~W})\right) ; \\
& \frac{\mathrm{d}^{2} \mathrm{~W}}{\mathrm{dt}^{2}}=\mathrm{a}_{2}=\frac{\alpha^{2}}{(1-\alpha)^{2}}\left(\mathrm{~S}_{\mathrm{t}}(\mathrm{W})-2 \mathrm{~S}_{\mathrm{t}}^{2}(\mathrm{~W})+\mathrm{S}_{\mathrm{t}}^{3}(\mathrm{~W})\right) .
\end{aligned}
$$

Let us set up initial condition:

$$
S_{0}^{1}(W)=S_{0}^{2}(W)=S_{0}^{3}(W)=W\left(t_{0}\right),
$$

here $\mathrm{W}\left(\mathrm{t}_{0}\right)$ - value of energy consumed which must correspond to the point from which the process of forecasting is initiated.

Qualitative indicators of forecasting may be identified in a standard way i.e. by mean-root square and maximum relative error. They may be defined proceeding from the below expressions:

$$
\begin{gathered}
e=\sqrt{\frac{\sum_{t=k+t^{*}}^{n}\left(P_{t}-P_{p r_{t}}\right)^{2}}{n-k-t^{*}-1} ;} \\
\delta_{\max }=\max _{t \in\left[k+t^{*}, n\right]} \frac{\left|W_{t}-W_{p r_{t} \mid}\right|}{W_{t}},
\end{gathered}
$$

where $\mathrm{n}$ - length of temporal series; $W_{t}$ and $W_{p r_{i}}$ - actual and predicted values of energy consumption; $\mathrm{k}$ - length of 
series of pre-predicted values (pre-history), t* - time of prediction.

Quality of prediction strongly depends on selection of $\alpha$ indicator which represents the smoothing parameter. Predicted values are differently accounting for effect exerted by preset data under analysis. For example, the more is $\alpha$, the more essential is the effect exerted by the latest values on the results of forecasting (the effect of preset indicators under analysis is decreasing).

Apart from $\alpha$ parameter the quality of prediction strongly depends on selection of $\mathrm{k}$ indicator (pre-history) used for forecasting.

According to the results of a priori analysis, in the majority of cases, for energy consumption schedules with discreteness $\Delta t$ equal to 24 hours and prediction advance time $t^{*}=\Delta t$ it is possible to accept $\alpha=0,3-0,5 ; \mathrm{k}=5-7$. These values of parameters are normally accepted as optimum $\left(\alpha_{\mathrm{opt}}, \mathrm{k}_{\mathrm{opt}}\right)$, which allows to predict the value of energy consumption with minimum error $\delta_{\max }$.

\section{RESULTS.}

This article addressed implementation of distributions and sample observation results analysis made with the use of STATISTICA software.

Fig.1 shows dependencies displaying variation of maximum relative prediction error $\delta_{\max }$ upon smoothing parameter $\alpha$ at different $\mathrm{k}$.

From dependencies presented in Fig. $1 \delta_{\max }=f(\alpha)$ it follows that minimum error $\delta_{\max }$ of prediction corresponds to $\alpha=0,2-0,4$ practically for entire indicators under consideration $k \in[2 ; 10]$. Minimum of relative error of the prediction $\delta_{\max }$ is achieved with $\mathrm{k}=6$.

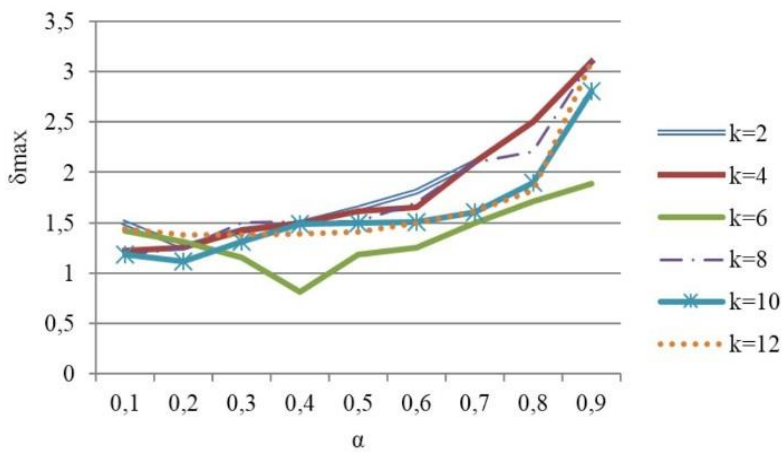

Fig.1. Dependencies of variation of value of maximum relative error $\delta_{\max }$ upon smoothing parameter $\alpha$.

Fig. 2 shows graphs which are reflecting the variation of value of maximum relative error $\delta_{\text {max }}$ of the prediction with reference to quantity of the points of pre-history $\mathrm{k}$.

Value of error $\delta_{\text {max }}=f(k), \mathrm{k}=2, \ldots, 10$ is expressed in percent of actual energy consumption values for various values of parameter $\alpha \in[0,1 ; 0,9]$. As can be viewed from Fig. 2, the error has minimum at values $k \in[5 ; 7]$.

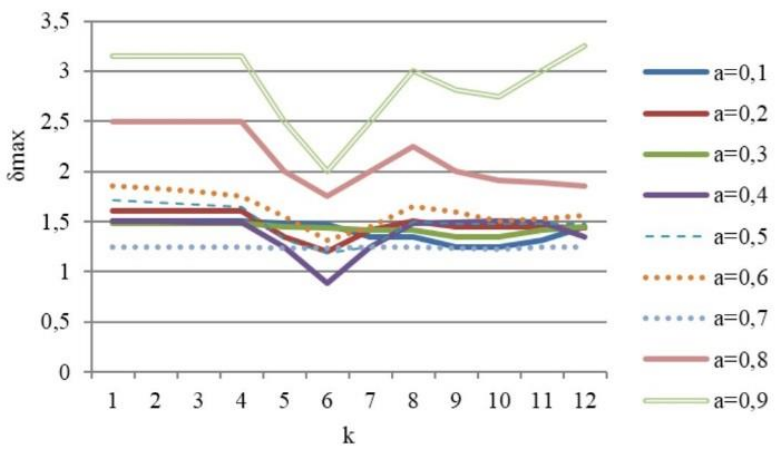

Fig. 2. Dependencies of variation of $\delta_{\max }$ on quantity of the points of pre-history $\mathrm{k}$

Researches show that for the analyzed processes of energy consumption variation limited quantity of $r$ intervals for which it is possible to make a prediction at $\mathrm{k}_{\mathrm{opt}}=6$ and $\alpha_{\mathrm{opt}}=0,2$, and $\Delta \mathrm{t}=1$ full day not exceeding the established algorithmic error $\delta_{\text {a max }}$ corresponds to two $(r=3)$ that is comprising 18 days of advance time.

Fig. 3 shows dependency of variation of maximum relative prediction error $\delta_{\max }$ upon quantity of prediction intervals $r$ at $k_{\mathrm{opt}}=6, \alpha_{\mathrm{opt}}=0.2$. Dashed line represents established limit value of algorithmic error.

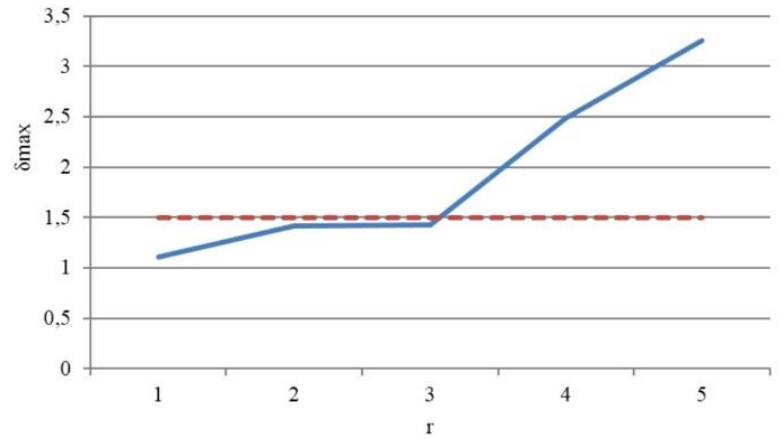

Fig. 3. Dependency of variation of maximum relative prediction error $\delta_{\text {max }}$ upon quantity of prediction intervals $r$ at $\mathrm{k}_{\mathrm{opt}}=6, \alpha_{\mathrm{opt}}=0,2$.

Optimized values $\mathrm{k}_{\mathrm{opt}}, \alpha_{\mathrm{opt}}$ to predict loads characterized by implementation of the process of variation thereof with temporal discreteness $\Delta \mathrm{t}=1$ full day allowing to obtain minimum values of prediction relative error $\delta_{\max }$ at different advance time $t^{*}$ have been established.

Dependencies $\delta_{\max }=f(\alpha)$ and $\delta_{\max }=f(k)$ have been analyzed, results are presented in Table 1 .

TABLE I. OPTIMIZED VALUES OF PARAMETERS OF FORECASTING BROWN'S FILTER $\mathrm{K}_{\mathrm{OPT}}, \mathrm{A}_{\mathrm{OPT}}$ FOR VARIOUS TIME ADVANCE INTERVALS R

\begin{tabular}{|c|c|c|c|c|c|}
\hline $\begin{array}{c}\text { Advance } \\
\text { interval }\end{array}$ & $\mathbf{r}=\mathbf{1}$ & $\mathbf{r = 2}$ & $\mathbf{r}=\mathbf{3}$ & $\mathbf{r}=\mathbf{4}$ & $\mathbf{r}=\mathbf{5}$ \\
\hline $\mathrm{k}$ & 4 & $9-10$ & $9-10$ & $13-15$ & $15-20$ \\
\hline$\alpha$ & 0.2 & $0.1-0.2$ & $0.1-0.2$ & $0.2-0.3$ & $0.1-0.2$ \\
\hline$\delta_{\max }, \%$ & $1.46 \%$ & $1.35 \%$ & $1.099 \%$ & $\begin{array}{c}2.59- \\
2.71 \%\end{array}$ & $\begin{array}{c}3.25- \\
3.29 \%\end{array}$ \\
\hline
\end{tabular}


From Table 1 it can be viewed that variation of advance interval $\mathrm{r}$ from 1 to 3 allows to perform a qualitatively satisfactory prediction at established parameters $\mathrm{k}_{\mathrm{opt}}=9-15$ and $\alpha_{\mathrm{opt}}=0.5-0.3$.

Prediction for five advance intervals demands twenty points of pre-history and cannot satisfy the preset accuracy of prediction $\delta_{a \max }$.

Thus, analyzed model of energy consumption prediction may be adaptable (by parameters) to various advance intervals.

Proceeding from prediction accuracy, the period of preparation and implementation of decisions regarding controlling actions which cannot drive the power grid dispatcher into tough time frame it is expected that acceptable advance interval will be $r=2,3$ which, at accepted discreteness interval of $\Delta \mathrm{t}$, corresponds to advance time $t^{*}$ equal to 2,3 full days.

Dispersion of predicted values $\mathrm{W} \Pi \mathrm{p}(\mathrm{t})$ of process $\mathrm{W}(\mathrm{t})$ for Brown's filter is characterized by dispersion value:

$D\left[W_{p r}(t)\right]=D(\varepsilon)\left[\alpha /(2-\alpha)^{3}\left(1+4(1-\alpha)+5\left(1-\alpha^{2}\right)+2 \alpha(4-3 \alpha) n+2 \alpha^{2} n^{2}\right)\right]$,

where $\varepsilon=W(t)-W_{T}(t)$ - difference between process of energy consumption and average component obtained from (2).

Dispersion of the predicted energy consumption allows to determine the confidence upper $\mathrm{W}_{\mathrm{B}}$ and lower $\mathrm{WH}_{\mathrm{H}}$ prediction boundaries

$$
W_{B, H}(t)=W_{T}(t) \pm t_{\beta} \sqrt{D\left[W_{p r}(t)\right]},
$$

where $t_{\beta}-$ critical Student's distribution point for $\mathrm{k}-2$ degrees of freedom at confidence level $\beta=0,05$.

According to the problem set, aiming to minimize falling of the consumed energy outside the standardized limit rates, let us use the upper boundary $\mathrm{W}_{\mathrm{B}}(\mathrm{t})$ of the predicted energy consumption value.

It should be mentioned that implementation of the energy management measures is leading to considerable variation of its character. As a consequence, characteristics of energy consumption variations revealed at the stage of examination are not maintained during further points of time. Direct usage of known statistical models $[16,17]$ in such situations is often proven to be inefficient.

Aiming to achieve the specified prediction accuracy in such conditions, it is expedient to make correction of initial data while developing the model. In this case, variation of consumed energy within the stage of model identification [ $t$ $-\mathrm{k} \Delta \mathrm{t} ; \mathrm{t}]$ must be represented in the form of two components

$$
\forall(t \in[t-k \Delta t ; t]) W(t)=W_{o}(t)+W_{\Sigma}(t),
$$

where $W_{O}(t)$ - total consumption of consumersregulators in respect of which there was no measures and actions undertaken i.e. connection/disconnection at the stage of pre-history $[t-k \Delta t ; t] ; W_{\Sigma}(t)-$ total energy consumption by consumers-regulators whose mode was changed at aforesaid stage.

Prediction is leading to formation of the list of measures and controlling actions which are directed towards railways power supply system which consists of a number of levels:

- traction substations;

- feeders of power supply and power distributions circuit;

- transformer substations;

- LV bus duct sections;

- LV feeders;

- groups of equipment which are supplied from one distribution device.

Assessment of quality of objects selection for energy management is performed with reference to criterion $\mathrm{F}(\mathrm{x})$ with components as follows:

$$
F_{1}(x)=\sum_{j=1}^{n} \sum_{i=1}^{m_{j}} y_{i j} k_{i j}, \quad F_{2}(x)=\sum_{j=1}^{n} \sum_{i=1}^{m_{j}} k_{i j},
$$

where $\mathrm{y}_{\mathrm{ij}}$ - value of damage during usage, for regulation, of $\mathrm{i}$-consumer at $\mathrm{j}$-level of the system; $\mathrm{k}_{\mathrm{ij}}$ - Boolean variable which takes on a value equal to 1 where $i$-consumer of $j$ level is used for energy consumption regulation or $0-$ otherwise; $\mathrm{m}_{\mathrm{j}}$ - quantity of consumers subject for regulation at j-level.

Optimization must be performed within the limits of specified value deviation from the value to be standardized:

$$
\sum_{j=1}^{n} \sum_{i=1}^{m_{j}} W_{i j} k_{i j} \geq \Delta W
$$

Using genetic, heuristic and statistic algorithms it is possible to select an optimized set of objects (consumersregulators) used for energy consumption volume regulation [10].

Generating of binary digit sets (lists of consumersregulators) must take place together with resulting list selection and initial data correction.

As a result, list of consumers (combination of power capacities and regulation duration) must compensate the obtained deviation of predicted value of power consumption from standardized.

\section{DISCUSSION}

Currently, entire transport sphere and railway transport, in particular, are undergoing the process of digital transformation resulting in emerging the blockchain technology, Internet of things, big data analytics, artificial intellect implementation, and increasingly advancing automation of transportation services with simultaneous growth of rendered services efficiency. Aforementioned technologies must be implemented not only with the purpose to achieve synergy effect resulting from simultaneous employment of entire possibilities but also for the purpose to obtain adequate functioning of various railway transport management systems because at the present stage of 
technical and technological development issues regarding provision of safe and trouble-free operation of digital systems have not been yet resolved to the full extent and require further studies. Artificial intellect and digital tools may not substitute the demand for high-quality service and technologies usage and it results in the necessity of continuous improvement of existing models used in transport management systems within the framework of the task to improve railway transport energy consumption efficiency.

Digital transformation of industry envisages advancement of digital twin-model systems allowing to aggregate information about the objects, charge the system by new data in on-line mode and, what is most important and perform modeling and prediction of technological processes based on analysis of the entire totality of data [18]. Digital twin-models are aggregating data obtained with the help of other digital technologies like Internet, blockchain and thus allow not only to efficiently respond to object (or group of objects) operation malfunction but represents the basis for situation modeling to avoid system malfunction and, accordingly, its efficiency loss.

There are three types of digital twins: prototypes, exemplars and aggregated twins [19]. While first two contain information about a physical object (description of technological processes, operational data, results of services provided etc.), the aggregated twin is representing a fullfledged digital system integrating a number of prototypes and exemplars within which analysis of all data available is carried out.

Digital twin-models enable (on railway transport facilities) optimization of transport sphere-related processes i.e. comprehensive monitoring of entire systems and vehicle stock, more efficient processing of input data resulting in railway transport management system improvement. Use of digital twin-systems in transport sphere allows timely responding to any external environment variations and what is most important to model and predicting technological processes. Therefore, these models represent the basis for resources optimization - financial, labor and material. Thus, elaboration of algorithms and models designed to improve energy management systems on railway transport is one of stages of digital twins' development within transport sphere upon which success of digital transformation of the given sector of economy strongly depends.

In 2019 a long term program of Russian Railways JSC development till 2025 was adopted. Directions of the aforesaid Program are reduction of energy consumption by existing technologies and reduction of energy-related operational expenses [3]. Railway transport energy efficiency index is holding 35\% in the integrated index of this Program efficiency; therefore, results of mathematical modeling of energy consumption on railway transport obtained herein are facilitating improvement of railway transport management systems aiming to achieve scheduled values envisaged by the program of this sphere digitization. Thus, by 2021 it is expected that energy efficiency of production activities carried out on the railway transport must increase by $2.6 \%$ [3].

In our opinion, digital transformation of energy consumption on railway transport assumes not only implementation of technological solutions analyzed herein but also demands attendant problems resolution. Firstly, implementation of modern digital technologies is associated with considerable initial expenses and risks of stranded costs. This barrier may be overcome by means of transport sphere digitization encouragement by the state through tax exemptions and other preferences aiming to intensify economical transformations.

Secondly, development of modern technologies demands scientific research works which appear to be very expensive. Solving of this problem may require state financial support in the form of research and investments aiming to activate technologies developed. Most part of businessmen prefers to refrain from investing in high-risk enterprises, especially innovative.

Thirdly, provision of information security on transport is also a key issue in the process of transport sphere modernization. Transport services require data confidentiality (it is mainly relating to railway transport) while fulfilling the state order, therefore, information security of technological solutions becomes a crucial issue. Moreover, modern energy management systems must be technically compatible with other systems integrated in the transport sphere and must be developing in the paradigm of technological solutions standardization so as to ensure a reliable, safe and user friendly application method.

Besides, application of mostly advanced technologies is often lacking a duly established legislative basis and this is impeding the process of economy digitization. Standards developed in the sphere of energy management on railway transport must (i) ensure systems security on national and international level and (ii) create conditions for further research in this direction.

Moreover, development and employment of modern energy management systems in transport sphere requires involvement of specialists capable to perform functional duties in new digital environment. Development of national human resources potential and advancement of educational programs within cooperation involving state, commercial organizations and educational institutions facilitate scientific research intensification in this sphere and create the basis for efficient functioning of emerging innovations in the practical sphere.

\section{CONCLUSIONS.}

This paper presents theoretical generalization enabling the reader to obtain analytical models adequately reflecting characteristics of electric energy consumption on railway transport which has significant importance for various sectors of economy.

It has been found that there are considerable differences in terms of industrial enterprise energy management methods, in particular, in regard of the railway transport [20].

Firstly, energy management system on the railway transport is more complicated if compared to others and has two levels [21].

Secondly, decrease gradient of energy consumption on the railway transport is sufficiently lower than that of industrial enterprises. Therefore, more short intervals of 
energy consumption analysis are required so as to ensure more accurate energy management process

Thirdly, objects intended for energy consumption controlling actions may be represented not only by nontraction consumers with "abnormal" energy consumption but by other facilities covered by the zone of activity of upper level of energy management on the railway transport. In our case it is necessary only to evaluate efficiency of controlling actions from the viewpoint of (i) aggregate damage minimization by means of mathematical modeling of prediction processes and (ii) damage assessment in the entire time interval.

Implementation of methodology of "intelligent" energy management on the railway transport with the use of digital tools will make it possible to improve efficiency of transportation, provide digital transformation on the railway transport with scientific base. Employment of approaches analyzed herein for the purpose of optimized controlling actions and measures identification will enable usage thereof within existing automated power consumption measurement systems and analysis, planning and energy consumption standardization systems.

Thus, one of directions of transport sphere digital transformation consists in modern technologies implementation in the sphere of energy management on railway transport. Advancement of digital technologies allows improving resources productivity, reducing material and financial costs and creates new opportunities aiming to derive benefits on the basis of modern innovative businessmodels within the framework of particular sectors of economy. Digitization of the transport sphere is emerging as a global trend demanding qualitatively new technological solutions and improvement of systems used; therefore, development of algorithmic models for energy management systems on railway transport is becoming one of the factors enabling intensification of the national transport system digital transformation.

\section{ACKNOWLEDGMENT}

The article was prepared as part of the work on the grant of the President of the Russian Federation NSh-4028.2018.6

\section{REFERENCES.}

[1] World Economic Forum, "The Digital Transformation of Industries: Digital Enterprise," 2016, p. 45.

[2] General Electric, "The Digital Energy Transformation,” 2018, p. 55.

[3] Decree of RF Government dated 19.03.2019 No. 466-p "Concerning approval of Program of "Russian Railways" JSC development till 2025," http://www.consultant.ru/document/cons_doc_LAW_320741/

[4] General Electric, "GE Power Outlook (Revision 6)," 2018.

[5] J. M. De Bedout, D. Frodl and B.N. Owens, "The Digital Grid and the Environment. Boston,” MA: General Electric, 2017, p. 21
[6] GESI, “\#SMARTer2030: ICT Solution for the 21st Century,” 2015, p. 135

[7] M. Knotek, A.P. Kopelevich, Ye.K. Maslovskiy and A.B. Cheliustkin "Problems of creation of automated production control systems," Moscow: International Center for Scientific and Technical Information, 1977, p. 64.

[8] V.A. Ivashchenko, M.V. Kolokolov and D.A. Vasiliev "Concept of synthesis of industrial enterprise automated energy management structure," Mechatronics, automation, control, No. 10, 2012, pp. 4346.

[9] W. Guo, T. Wenning, S. Nimbalkar, K. Thirumaran, K. Armstrong and E. Levine, "A New Methodology for Calculating The Energy Performance of Manufacturing Facilities," Energy Engineering, vol. 116( 2), 2019, pp. 7-21, DOI: 10,1080,01998595,2019,12054402.

[10] G. S. Shehu and N. Çetinkaya, "A comparison of Improved NatureInspired Algorithms for Optimal Power System Operation," Control Engineering and Applied Informatics, vol. 20( 4), 2018, pp. 50-59.

[11] K.B. Mansimov and M.Y. Nacafova, "Quasi-singular control in discrete systems control problem with nonlocal boundary conditions," Tomsk State University Journal of Control and Computer Science, Vol. 46, 2019, pp. 4-11, DOI: 10.17223/19988605/46/1.

[12] N.V. Byshov and D.Ye. Kashirin "Issues regarding the theory of energy saving, convective cyclic beebread drying": monography, Ryazan: Publishing house of Ryazan state agrotechnological University, 2012, p. 70.

[13] N.V. Byshov, F.A. Musayev, V.V. Tekushev and L.V. Cherkashina "Information technologies in economy and management": laboratory course, Ryazan, 2015, p. 184.

[14] S. A. Parker, "Ideas that Work-Back to Basics," Energy Engineering, vol. 112(6), 2015, pp. 7-10, DOI: $10.1080 / 01998595.2015 .11494383$

[15] Q. Wang, Y. Zheng, S. Wu and T. Li, "Mechanism of energy efficiency response to industrial restructuring and energy consumption structure change," ActaGeographicaSinica, vol. 66(6), 2011, pp. 741-749.

[16] V.G. Sazykin "Intellectualization of automatic design systems for power facilities: Multivariable fuzzy concept," Energetics , No. 9, 1994, pp. 14-20.

[17] W. Guo, T. Wenning, S. Nimbalkar, K. Thirumaran, K. Armstrong and E. Levine, "Comparison of One- and Two-Variable Linear Regression Models and Classic Energy Intensity for Energy Performance Tracking of Two Manufacturing Sectors," Energy $\begin{array}{lllll}\text { Engineering, vol. } & 115 & \text { (5), } & 2018, & \text { pp. }\end{array}$ DOI: $10.1080 / 01998595.2018 .12027705$.

[18] V.P. Kupriyanovskiy, V.V.Alenkov, A.A. Klimov, I. A. Sokolov and A.V. Zazhigalkin "Digital railway - ertms, bim, GIS, PLM and digital twins," Modern information technologies abd IT-education, vol. 13, No. 3, 2017, pp. 129-166.

[19] I. Peshkova "How digital twins help Russian industry," Rusbase, 2019, https://rb.ru/longread/digital-twin/.

[20] S.B. Mukhambetov "Energy management on railway transport," Science and engineering on transport, No. 4, 2006, pp. 42-43.

[21] I.K. Danilov "Some aspects regarding decision making within the theory of multi-level hierarchical systems," Re-engineering and strengthening of machine components: interacademic scientific collection, Saratov: Saratov state technical University, 2000, pp. 4045 . 